\title{
Resource contrast in patterned peatlands increases along a climatic gradient
}

\author{
Maarten B. Eppinga, ${ }^{1,2,6}$ Max Rietkerk, ${ }^{1}$ Lisa R. Belyea, ${ }^{3}$ Mats B. Nilsson, ${ }^{4}$ Peter C. De Ruiter, ${ }^{5}$ \\ And Martin J. Wassen ${ }^{1}$ \\ ${ }^{1}$ Department of Environmental Sciences, Copernicus Institute, Utrecht University, P.O. Box 80115, 3508 TC Utrecht, The Netherlands \\ ${ }^{2}$ Department of Plant Biology, University of Vermont, 109 Carrigan Drive, Burlington, Vermont 05405 USA \\ ${ }^{3}$ Department of Geography, Queen Mary University of London, Mile End Road, London E1 4NS United Kingdom \\ ${ }^{4}$ Department of Forest Ecology and Management, Swedish University of Agricultural Sciences, S-901 83 Umeå, Sweden \\ ${ }^{5}$ Biometris, Wageningen University, P.O. Box 100, 6703 BD Wageningen, The Netherlands
}

\begin{abstract}
Spatial patterning of ecosystems can be explained by several mechanisms. One approach to disentangling the influence of these mechanisms is to study a patterned ecosystem along a gradient of environmental conditions. This study focused on hummock-hollow patterning of peatlands. Previous models predicted that patterning in drainage-dominated peatlands is driven by a peat-accumulation mechanism, reflected by higher nutrient availability in hollows relative to hummocks. Alternatively, patterning in evapotranspiration (ET)-dominated peatlands may be driven by a nutrient-accumulation mechanism, reflected by reversed nutrient distribution, namely, higher nutrient availability in hummocks relative to hollows. Here, we tested these predictions by comparing nutrient distributions among patterned peatlands in maritime (Scotland), humid temperate (Sweden), and humid continental (Siberia) climates. The areas comprise a climatic gradient from very wet and drainage-dominated (Scotland) to less wet and ET-dominated (Siberia) peatlands. Nutrient distribution was quantified as resource contrast, a measure for hummock-hollow difference in nutrient availability. We tested the hypothesis that the climatic gradient shows a trend in the resource contrast; from negative (highest nutrient availability in hollows) in Scotland to positive (highest nutrient availability in hummocks) in Siberia. The resource contrasts as measured in vegetation indeed showed a trend along the climatic gradient: contrasts were negative to slightly positive in Scotland, positive in Sweden, and strongly positive in Siberia. This finding corroborates the main prediction of previous models. Our results, however, also provided indications for further model development. The low concentrations of nutrients in the water suggest that existing models could be improved by considering both the dissolved and adsorbed phase and explicit inclusion of both nutrient-uptake and nutrient-storage processes. Our study suggests that future climate change may affect the ecosystem functioning of patterned peatlands by altering the contribution of pattern-forming mechanisms to redistribution of water and nutrients within these systems.
\end{abstract}

Key words: empirical test; evapotranspiration; hummock-hollow pattern; model predictions; patterned peatlands; resource contrast; Scotland; Siberia; spatial patterns; Sweden.

\section{INTRODUCTION}

A key challenge in ecology is to explain large-scale patterns that emerge from small-scale mechanisms (Levin 1992, Solé and Bascompte 2006). Spatial patterns of sessile biota that are regular or otherwise coherent are among the most striking large-scale patterns and have been observed in a variety of ecosystems (Rietkerk and Van de Koppel 2008). This large-scale patterning is an important determinant of ecosystem functioning (Van de Koppel et al. 2008) and biodiversity (Solé and Bascompte 2006). To predict how patterned ecosystems respond to changes in external forcing, such as climate

Manuscript received 21 July 2009; revised 26 October 2009; accepted 9 November 2009. Corresponding Editor: J. B. Yavitt.

${ }^{6}$ E-mail: Maarten.Eppinga@uvm.edu change, identification of smaller-scale mechanisms may be essential (Rietkerk et al. 2004a, Belyea and Baird 2006). One common small-scale mechanism that can explain ecosystem patterning is concentration of limiting resources by sessile biota (Rietkerk et al. 2004a, Shachak et al. 2008). A classical problem, however, is that several mechanisms may be capable of explaining the same ecosystem pattern (Levin 1992, Rietkerk and Van de Koppel 2008) and which of these mechanisms drives pattern formation in reality may change with changing environmental conditions (Eppinga et al. 2009a, b). An approach to disentangling the influence of several mechanisms is to study a particular type of patterned ecosystem along a gradient of environmental conditions, when it can be expected that the contribution of the underlying mechanisms to the observed ecosystem pattern will change along this gradient. 
In peatland ecosystems, spatial surface and vegetation patterning with a characteristic spatial scale of 10-100 m is frequently observed (e.g., Sjörs 1961). This pattern consists of elevated, relatively dry and densely vegetated patches (hummocks or ridges), alternating with lower and less densely vegetated patches (lawns) or sparsely vegetated wet depressions (hollows). Peatland patterns of hummocks/ridges with lawns and hollows occur in various spatial arrangements, including scattered individual hummocks, lawns and hollows (e.g., Belyea and Clymo 2001), maze-like ridges arranged within a matrix of hollows (e.g., Rietkerk et al. 2004b) and linear ridgehollow patterns along the contours of slopes (e.g., Sjörs 1961).

Most of the incoming precipitation in peatlands is lost through either evapotranspiration (ET) or drainage (Ingram 1983). The proportion of precipitation lost through ET (hereafter referred to as the "ET:Prec ratio") is constrained by peatland slope and climate (Reeve et al. 2000, Belyea and Malmer 2004, Belyea 2007). Hence, the ET:Prec ratio differs along climatic gradients. If the climate imposes a low ET:Prec ratio, water losses are dominated by drainage over ET (hereafter referred to as "drainage-dominated"). If the climate imposes a high ET:Prec ratio, water losses are dominated by ET over drainage (referred to from here as ET-dominated). Under the latter conditions, ET may influence advection of peatland water during relatively dry (summer) periods (Eppinga et al. 2008), and thereby be an important mechanism to redistribute nutrients (Rietkerk et al. 2004b, Wetzel et al. 2005).

Model studies suggest that in ET-dominated peatlands, patterning is driven by a resource-concentration mechanism (Rietkerk et al. 2004b). The presence of vascular plants (in particular trees and shrubs) on hummocks may induce higher ET rates relative to hollows (Wetzel et al. 2005). Hence, water and dissolved nutrients flow from hollows to hummocks. Subsequently, nutrients become trapped on hummocks through uptake by vascular plants. Thus, during their life span, vascular plants that grow on hummocks accumulate nutrients originating from outside the hummocks. Nutrients become available again through mineralization of vascular plant litter, but this increases nutrient availability only locally (within the hummock). Models predict that this local recycling effect outweighs the effect of nutrient uptake, meaning that nutrient concentrations in peatland water under hummocks also increase (Rietkerk et al. 2004b, Eppinga et al. 2008). This resource-concentration mechanism was named the nutrient-accumulation mechanism (Rietkerk et al. 2004b). In a previous study, field data from an ET-dominated patterned peatland (Siberia) corroborated the presence of a nutrient-accumulation mechanism; nutrient availability (in water and vegetation shoots) was higher in hummocks than in hollows (Eppinga et al. 2008).

Peatland patterning, however, also occurs in regions with a low ET:Prec ratio. It is unlikely that patterning in these regions is driven by the nutrient-accumulation mechanism. A recent model study (Eppinga et al. 2009a) revealed that peatland patterning could also be driven by a positive feedback between acrotelm thickness and net rate of peat formation (Belyea and Clymo 2001, Larsen et al. 2007). This peat-accumulation mechanism is expected to be the most important driver of patterning in drainage-dominated peatlands (Eppinga et al. 2009a). Water losses through drainage and overland flow are highest from hollows (Foster et al. 1983, Quinton and Roulet 1998, Belyea and Malmer 2004). Hummocks may form due to the peat-accumulation mechanism, but in drainage-dominated systems these hummocks may survive only if they can partially drain excess water toward neighboring hollows (Belyea and Clymo 2001, Eppinga et al. 2009a). In this case, a net transport of water from hummocks to hollows is required. Because transport of water implies transport of dissolved nutrients as well, this would lead to lower nutrient concentrations in hummocks relative to hollows (Eppinga et al. 2009a).

Hence, these model results predict that the mechanism of pattern formation differs between drainage-dominated peatlands and ET-dominated peatlands, and that this difference in mechanisms is reflected in the nutrient distribution (Eppinga et al. 2009a). The aim of our present study was to test this hypothesis by performing the same kind of measurements as previously conducted in Siberia (measurements of nutrient availability in peatland water and vegetation shoots, Eppinga et al. 2008) in patterned peatlands with lower ET:Prec ratios. More specifically, we compared the nutrient distribution as previously observed in a humid continental climate (Siberia) with new observations in maritime (Scotland) and humid temperate (Sweden) climates. The lowest ET:Prec ratio is found in the Scottish site (Table 1). Previous research suggests the absence of the nutrientaccumulation mechanism in this area (Belyea 2007). Together with the Swedish study area (intermediate ET:Prec ratio, Table 1), the three study areas comprise a gradient in the ET:Prec ratio, mainly through their difference in annual precipitation (Table 1).

A straightforward quantification of the nutrient distribution in a patterned ecosystem is the resource contrast (Shachak et al. 2008, Van der Valk and Warner 2009). For peatlands, resource contrast refers to the difference in nutrient availability between hummocks and hollows. If patterning is driven by the nutrientaccumulation mechanism, this is reflected by a positive resource contrast (nutrient availability is higher in hummocks than in hollows). If patterning is driven by the peat-accumulation mechanism, this is reflected by a negative resource contrast (nutrient availability is lower in hummocks than in hollows). Based on previous theory, we hypothesized that the resource contrast changes along the gradient in ET:Prec ratio, from negative in Scotland to positive in Siberia (Table 1). 
TABLE 1. Overview of the study sites, which comprise a gradient with respect to the importance of evapotranspiration in the water balance.

\begin{tabular}{|c|c|c|c|c|c|}
\hline Study site & Prec. $(\mathrm{mm})$ & $\mathrm{ET}(\mathrm{mm})$ & ET:Prec. ratio & $\begin{array}{c}\text { Expected main } \\
\text { driving mechanism }\end{array}$ & $\begin{array}{c}\text { Expected resource } \\
\text { contrasts }\end{array}$ \\
\hline Scotland & $1700^{1}$ & $\begin{array}{l}380 \dagger^{1} \\
250 \dagger^{1}\end{array}$ & $0.15-0.22$ & peat accumulation $^{1,2}$ & negative $\S^{2}$ \\
\hline Sweden & $\begin{array}{c}520^{3} \\
546-936^{4}\end{array}$ & $227-337^{4}$ & $0.25-0.62$ & (no data) & intermediate \\
\hline Siberia & $500^{5}$ & $300-500^{5}$ & $0.60-1.00$ & nutrient accumulation $\#^{2,6,7}$ & positive $\|^{2,6,7}$ \\
\hline
\end{tabular}

Notes: Study sites were Inverewe (Scotland), Degerö Stormyr (Sweden), and the Great Vasyugan Bog (Siberia). Key to abbreviations: Prec., precipation; ET, evapotranspiration. The ET:Prec. ratio indicates the importance of evapotranspiration. Hypotheses were based on data available from previous studies (indicated by superscript numbers).

Sources: 1, Belyea (2007); 2, Eppinga et al. (2009a); 3, Granberg et al. (2001); 4: Sagerfors (2007); 5, Semenova and Lapshina (2001); 6, Eppinga et al. (2008); 7, Eppinga et al. (2009b).

$\uparrow$ Hollows.

\pm Hummocks/ridges.

$\S$ Meaning lower nutrient availability in hummocks than in hollows.

\# Together with peat-accumulation mechanism.

- Meaning higher nutrient availability in hummocks than in hollows.

\section{Material And Methods}

\section{Field measurements and laboratory analyses}

We sampled patterned peatlands in three study areas (Fig. 1; Table 1): Inverewe (Scotland), Degerö Stormyr (Sweden), and the Great Vasyugan Bog (Siberia). Descriptions of these study areas are given in Appendix A. In Siberia we sampled a pattern on a relatively flat terrain. In Scotland and Sweden, we sampled patterns on both relatively flat terrain and slopes. Thus, in total we sampled five pattern-localities. The term "patternlocality" refers to a combination of pattern ("flat ground" or "slope") and study area (Scotland, Sweden or Siberia). Within pattern-localities on flat ground, field measurements were taken along transect sets, each set consisting of two orthogonal transects crossing at their midpoints. For the pattern in Siberia, a transect consisted of the halves of two ridges and the hollow in between. We selected three measurement points on each ridge, and five points in each hollow. In the Swedish and Scottish pattern-localities, each microform had one measurement point. For the pattern on flat ground in Sweden, we sampled three transect sets. Here, the pattern consisted of an irregular two-phase mosaic of hummocks and lawns, and therefore we sampled these microforms alternately along each transect. In Scotland, we sampled two transect sets. Here, the pattern consisted of an irregular three-phase mosaic of hummocks, lawns, and hollows, and therefore there was no regular order of sampling microforms. In both Scotland and Sweden, the orientation of the first transect of a set was selected at random.

For pattern-localities on slopes (only in Scotland and Sweden) we sampled transects oriented along the slope of a linear pattern. These patterns consisted of twophase mosaics, and therefore we sampled ridges and wetter microforms (lawn or hollow) alternately along each transect. In total, the sampling design comprised 403 measurement points (Appendix A).
At each measurement point we measured $\mathrm{pH}$, electrical conductivity (EC), temperature directly in the peatland water, and alkalinity by titration (Aquamerck alkalinity field set; Merck Chemicals, Darmstadt, Germany). Further, a water sample was taken from within $5 \mathrm{~cm}$ of the water table. Samples were acidified within 8 hours and later analyzed in the laboratory for the concentrations of constituents using an inductively coupled plasma technique (ICP-OES) as described in Eppinga et al. (2008). The only methodological difference for the analysis for different localities was that water samples from Scotland and Sweden were filtered (0.2- $\mu \mathrm{m}$ nylon filter; mdi, Ambala Cantt, India) within 8 hours of collection whereas those from Siberia were centrifuged in the laboratory. This difference, however, did not affect the results of our study (see Appendix B for details).

Around each measurement point we harvested 10 vegetation shoots. We selected healthy-looking newly grown shoots (i.e., from the current growing season), to avoid effects of nutrient resorption processes (Jonasson and Shaver 1999). Unfortunately there was no single species that was present in all study areas. Instead, we sampled in each study area a species from the sedge family (Cyperaceae) that was present on all microforms of that area. We sampled Rhynchospora alba in Scotland, Eriophorum vaginatum in Sweden, and Carex lasiocarpa in Siberia. Vegetation samples were dried for one week at $70^{\circ} \mathrm{C}$. Then the concentrations of the macronutrients nitrogen $(\mathrm{N})$, phosphorus $(\mathrm{P})$, and potassium $(\mathrm{K})$ were determined. The tissue concentration of $\mathrm{N}$ was determined with a dynamic flash combustion technique. Tissue concentrations of $\mathrm{P}$ and $\mathrm{K}$ were determined with ICP-OES, after a digestion procedure that is described in Eppinga et al. (2008). The type of nutrient limitation was determined based on thresholds in the $\mathrm{N}: \mathrm{P}, \mathrm{N}: \mathrm{K}$, and $\mathrm{K}: \mathrm{P}$ ratios in the tissue (Olde Venterink et al. 2003, Wassen et al. 2005). The $\mathrm{N}: \mathrm{P}$ ratio in aboveground vascular plant biomass is considered to be a reliable indicator of nutrient 


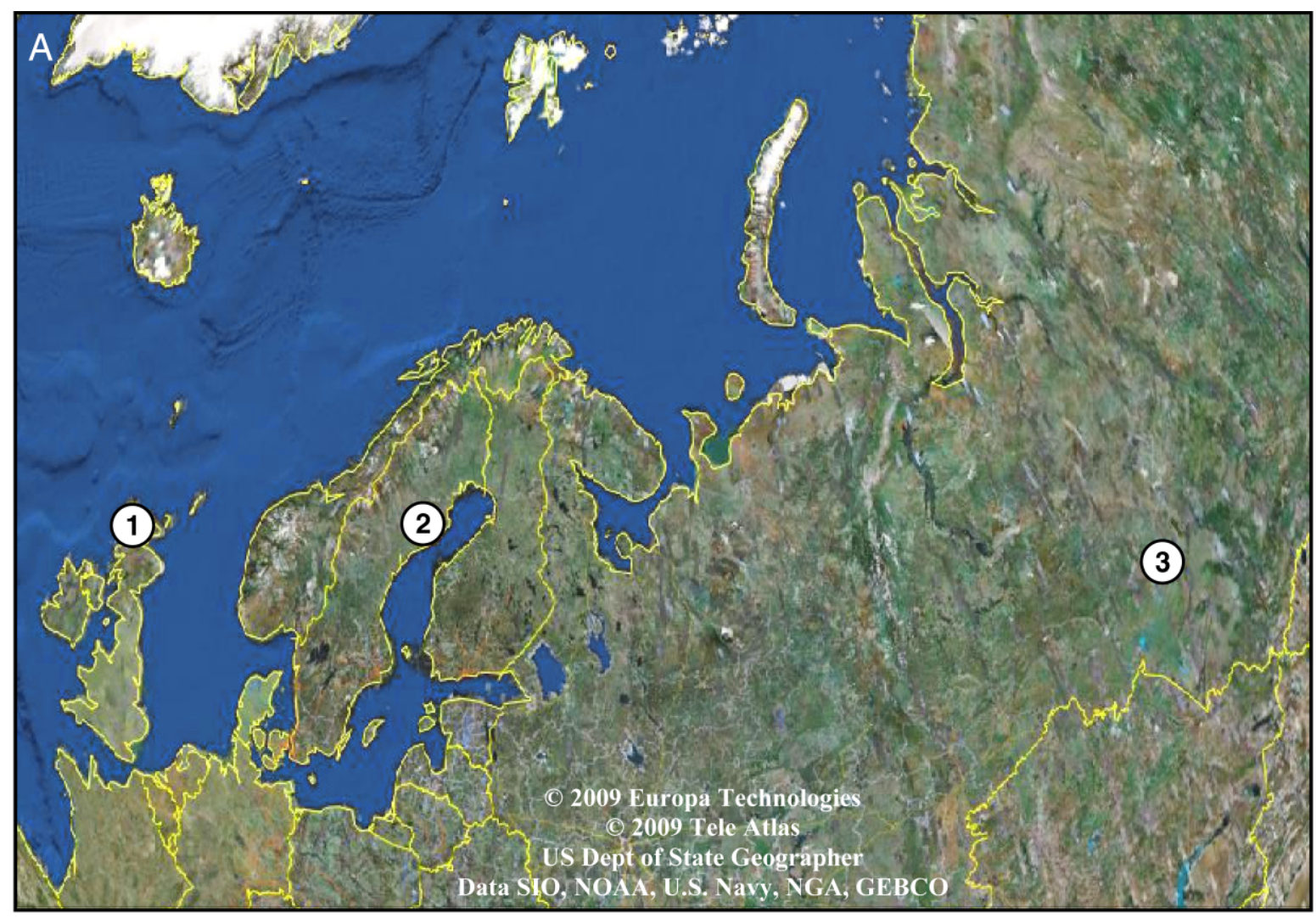

(1)

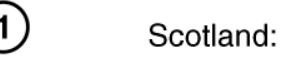
flat (B) and slope (C)

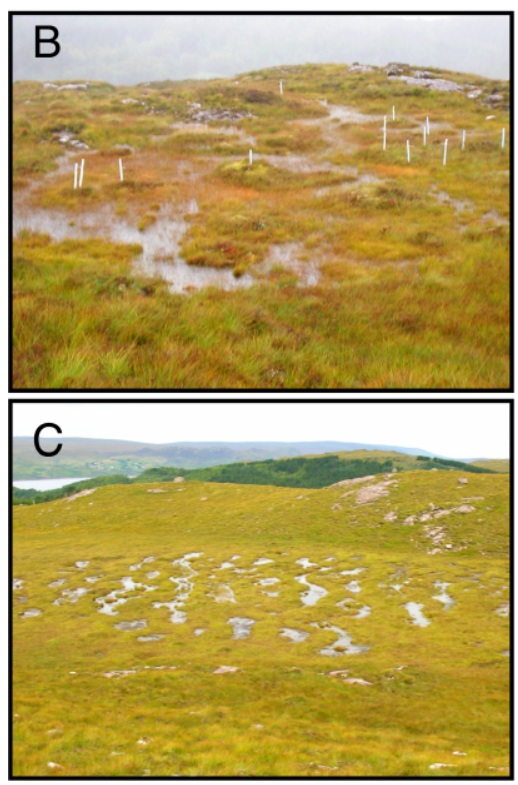

(2) flat (D) and slope (E)

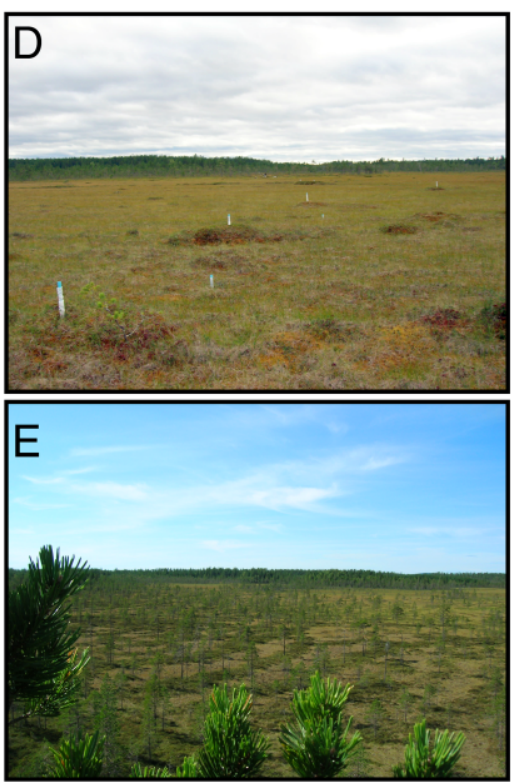

(3) flat from the air $(F)$ and ground $(G)$

FIG. 1. (A) Satellite image showing the study areas. Three different study areas were sampled: (1) Inverewe, Scotland (57 $46^{\prime}$ N,

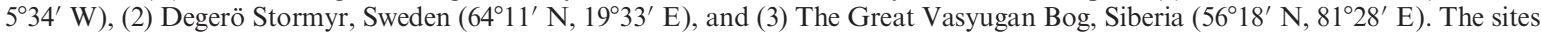
comprise a gradient with respect to the importance of evapotranspiration (ET) for water loss, expressed as the ratio between evapotranspiration and precipitation (the ET:Prec ratio). The ET:Prec ratio is relatively small in the maritime climate of Scotland, and relatively large in the humid continental climate of Siberia. In Scotland and Sweden we sampled two types of patterns: a hummockhollow pattern on flat ground (B, D) and a linear hummock-hollow pattern on slopes (C, E). In Siberia, we sampled a maze pattern of hummocks and hollows on flat ground (F, G). (Panel A was derived from Google Earth; panels B-G photos were taken by M. Eppinga.) 
limitation in wetlands (Güsewell and Koerselman 2002). The method, however, is most suitable for total vascular-plant biomass samples rather than single species samples (Güsewell and Koerselman 2002). Therefore, we also determined the $\mathrm{N}: \mathrm{P}$ ratios in a small number of total nonwoody vascular plant biomass harvests on $40 \times 40 \mathrm{~cm}$ plots in the Scottish $(n=10)$ and Swedish $(n=7)$ pattern-localities.

\section{Comparisons and statistical treatment}

For nutrient concentrations in the peatland water and for nutrient concentrations and nutrient ratios in the plant tissue, we tested for differences between microforms within each of the five pattern-localities. For the pattern on flat ground in Scotland we aggregated the measurements of lawns and hollows into one "hollow" group. Whether these two groups were lumped or not had no effect on the conclusions of this study, but it eased presentation of the results, because all patternlocalities then consisted of two microform groups. Statistical analyses were done with the software SPSS (version 14.0; SPSS 2001). For all comparisons, homogeneity of variances between groups was tested with the Levene test statistic. If variances were homoscedastic at the $\alpha=0.05$ significance level, differences were tested with one-way ANOVA. Otherwise we used the nonparametric Mann-Whitney $U$ test.

Further, we tested for differences in the hummock : hollow resource contrasts between the five pattern-localities with respect to nutrients. For these differences in resource contrast, we could not perform a standard factorial ANOVA approach, for three reasons. First, our study design was unbalanced, because we did not sample a pattern on peatland slopes in Siberia. Second, a factorial ANOVA does not correct for differences in nutrient availability between sites. Third, a factorial ANOVA would require replicate paired measurements of hummock-hollow pairs, which was not our sampling design. Therefore, we calculated for each pattern-locality a resource contrast, which represents a relative measure of the hummock-hollow difference in nutrient availability. Because the resource contrast is a relative measure, it corrects for differences in overall nutrient availability between pattern-localities. The resource contrast (RC) for a resource $X$ within a pattern-locality was calculated as

$$
\mathrm{RC}_{X}=\frac{\overline{\left(X_{\text {hummock }}-X_{\text {hollow }}\right)}}{\overline{X_{\text {hummock }}}+\overline{X_{\text {hollow }}}}
$$

where $\mathrm{RC}_{X}$ is a dimensionless unit for the contrast in resource $X$ in a pattern-locality, and overbars indicate averages. The value of $\mathrm{RC}_{X}$ can range between -1 (which means no resources in the hummocks) and 1 (which means no resources in the hollows). Differences in resource contrast between two pattern-localities can be tested by comparing the $\mathrm{RC}$ values and their standard deviations. We used a bootstrap technique to estimate the $\mathrm{RC}$ and its standard deviation (Efron and Tibshirani
1993). The mean and the standard deviation of the RC of each pattern-locality depend on the pair-wise coupling of hummocks and hollows (indicated by the overbar in the numerator of Eq. 1). In our study, however, hummocks and hollows were not paired. Hence, we constructed bootstrap replicates by sampling hummock-hollow pairs (with replacement) from the original data (Efron and Tibshirani 1993), using the random permutation function as implemented in MATLAB (version 7.7.0; MathWorks 2008). We generated 100000 bootstrap replicates, because at this point the average $\mathrm{RC}$ and the average standard deviation had stabilized to the fourth significant digit. We could then test for significant differences between sites using a $t$ test for two populations. Because multiple comparisons were made (10 pairwise comparisons between five pattern-localities) we subsequently performed a Bonferroni adjustment.

\section{Results \\ Type of nutrient limitation}

In all five pattern-localities, the majority of measurement points $(84 \%)$ indicated phosphorus $(\mathrm{P})$ limitation (Fig. 2). Co-limitation by nitrogen (N), however, did also occur (12.5\% of measurement points, Fig. 2). Vegetation on the hummocks in the Siberian pattern was on average co-limited by $\mathrm{N}$ and $\mathrm{P}$, vegetation on all other microforms in all other pattern-localities was on average P-limited. In all pattern-localities, N:P ratios in plants growing on hummocks were significantly lower as compared to hollows (data not shown), suggesting that hollows were more strongly limited by $\mathrm{P}$. The N:P ratios in total vascular plant biomass harvested from $40 \times 40$ $\mathrm{cm}$ plots in the Scottish and Swedish pattern-localities also indicated P limitation (Scotland, mean N:P of 27.2; Sweden, mean N:P of 21.3). It can be concluded that $\mathrm{P}$ is most limiting for plant growth.

\section{Resource contrast}

$\mathrm{P}$ concentrations in water were very low in the pattern-localities in Sweden (62\% of the measurement points below the detection limit of $0.03 \mathrm{mg} \mathrm{P} / \mathrm{L}$ ) and Scotland ( $89 \%$ below the detection limit). In general, nutrient concentrations were highest in water under hummocks (Fig. 3). Further, vegetation growing on hummocks had a higher tissue $\mathrm{P}$ concentration as compared to hollows, but out of all patternlocalities, $\mathrm{N}$ and $\mathrm{K}$ were significantly higher in hummock vegetation only in the Siberian patternlocality (Fig. 3).

There were no trends in the resource contrast for the nutrients in peatland water (Fig. 4A-C). For P, both the smallest and largest resource contrasts occurred in Scotland (Fig. 4A), suggesting that the gradient in ET:Prec ratio had little influence on the contrast in peatland water $\mathrm{P}$ concentration. Trends were also absent for peatland water concentrations of $\mathrm{N}$ and $\mathrm{K}$ (Fig. $4 \mathrm{~B}, \mathrm{C})$. However, there were trends in the resource contrasts for nutrient concentration in vegetation (Fig. 


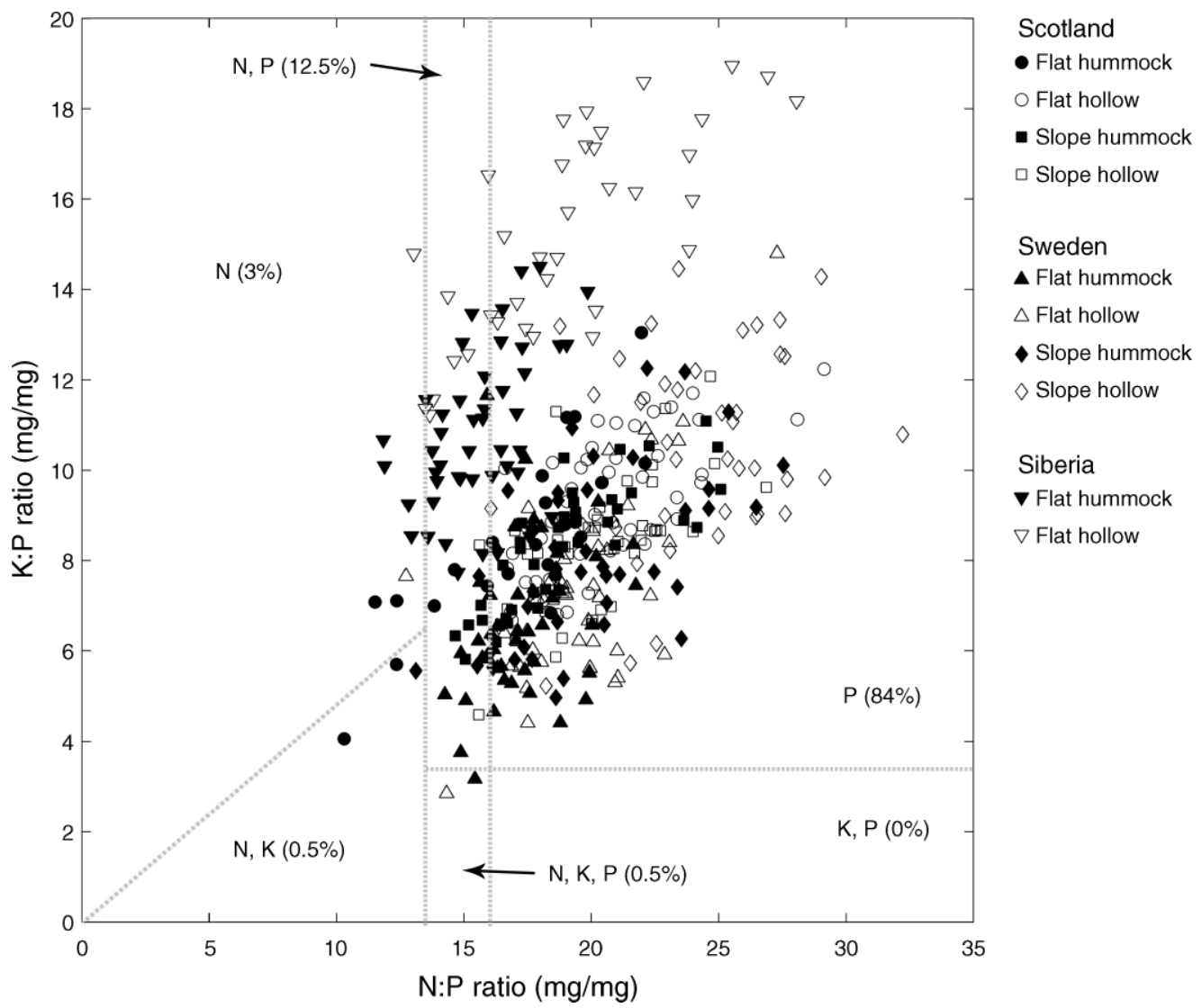

FIG. 2. Nutrient ratios within the tissue of plants growing on hummocks (solid symbols) and hollows (open symbols) in different types of patterned peatlands. Rhynchospora alba was sampled in Scotland, Eriophorum vaginatum in Sweden, and Carex lasiocarpa in Siberia. The dotted gray lines separate regions with different kinds of nutrient limitation (based on Olde Venterink et al. [2003] and Wassen et al. [2005]). The prevalence of nutrient limitation by nitrogen (N), phosphorus (P), or potassium (K) is given in parentheses; more than one nutrient indicates co-limitation. On average, all three study areas were P limited. Further, lawns and hollows were more strongly limited by $\mathrm{P}$ than were hummocks/ridges.

4D-F). In general, resource contrasts changed from negative to positive along the gradient in ET:Prec ratio, ranging from low in Scotland to high in Siberia (Fig. 4D-F). Resource contrasts were negative (i.e., lower nutrient concentrations in hummocks than in hollows) or slightly positive in Scotland, positive (i.e., higher nutrient concentrations in hummocks than in hollows) in Sweden, and strongly positive in Siberia (Fig. 4D-F). This trend was qualitatively the same for tissue $\mathrm{P}, \mathrm{N}$, and $\mathrm{K}$ concentration. The only exception occurred for tissue $\mathrm{P}$ concentration in the Scottish pattern on flat ground, for which the contrast was similar to the Swedish pattern-localities (but smaller than the Siberian pattern; Fig. 4D).

Interestingly, the effect of topography (flat ground vs. slope) differed between the Scottish and Swedish pattern-localities (Fig. 4). Resource contrasts in vegetation in Scotland tended to be lower on slopes, whereas the contrasts in Sweden tended to be lower on flat ground (Fig. 4).

\section{Discussion}

\section{Comparison of field data with previous model results}

Our results indicated that resource contrasts in the vegetation of hummock-hollow patterned peatlands changed from negative to positive along a climatic gradient from low to high evapotranspiration: precipitation (ET:Prec) ratio (Table 1; Fig. 4D-F). At the lower end of this gradient, vegetation growing in hollows had equal or higher tissue nutrient concentration as compared to hummocks, whereas at the upper end of the gradient, tissue nutrient concentration was much higher in vegetation growing on hummocks (Fig. 4D-F). These results are in line with the hypothesis that, in ETdominated peatlands, patterning may be driven by a nutrient-accumulation mechanism (Wetzel et al. 2005). Theoretical studies have shown that such a resourceconcentration mechanism can induce patterning in several ecosystems (Rietkerk and Van de Koppel 2008), which should be reflected in the resource contrast 

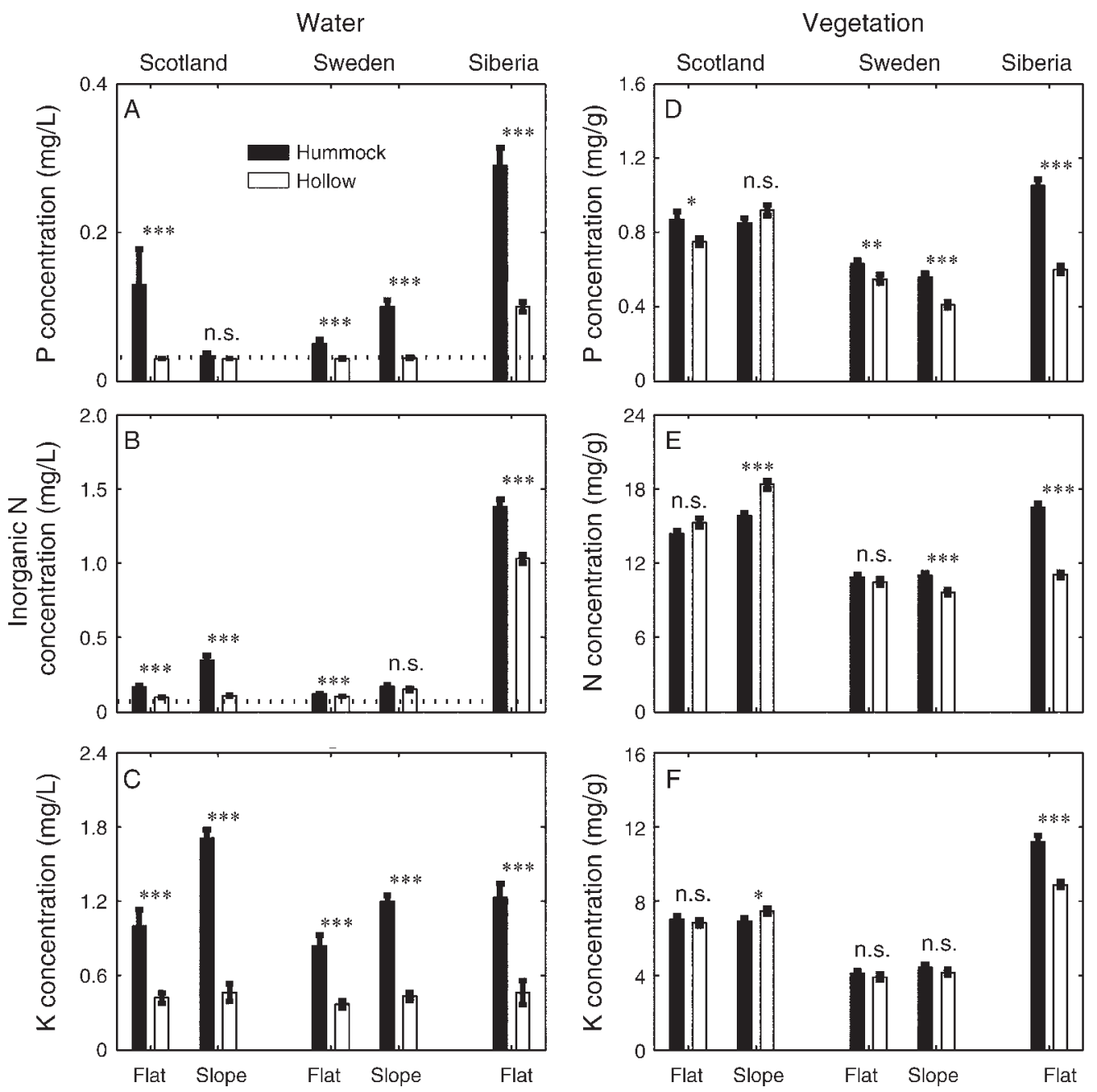

FIG. 3. Nutrient concentrations in peatland water (left-hand panels, A-C) and vegetation (right-hand panels, D-F) as measured on hummocks and hollows in patterned peatlands in Scotland, Sweden, and Siberia. Solid bars represent hummocks, and open bars represent hollows; error bars indicate \pm SE. The broken horizontal black lines indicate the detection limits for $\mathrm{P}(0.03 \mathrm{mg} /$ $\mathrm{L})$ and inorganic $\mathrm{N}(0.08 \mathrm{mg} / \mathrm{L})$ concentrations in the peatland water. Asterisks indicate significant differences between hummocks and hollows.

${ }^{*} P<0.05 ;{ }^{* *} P<0.01 ; * * * P<0.001 ;$ n.s., nonsignificant.

(Shachak et al. 2008, Van der Valk and Warner 2009). Our present study is the first comparison of resource contrasts in patterned ecosystems along an environmental gradient.

The data from the Scottish and Swedish sites revealed nutrient-poor circumstances; the $\mathrm{P}$ concentrations in peatland water were mostly below the detection limit. Nutrient availability is therefore determined by the nutrient replenishment rate rather than the actual size of the dissolved nutrient pool (Binkley and Hart 1989). As a result, annual nutrient uptake by plants may be orders of magnitude larger than the dissolved-nutrient pool (Bridgham et al. 2001). Under such circumstances, the most reliable indicator of nutrient availability is the tissue nutrient concentration in annual vegetation shoots
(Wassen et al. 1995, Güsewell and Koerselman 2002). In other words, the measured resource contrasts in peatland water may reflect transient events, whereas the measured resource contrasts in the vegetation may reflect the effect of longer term ecosystem processes. Therefore, the resource contrasts in vegetation are most useful in identifying dominant feedback mechanisms. Our results support the notion that the mechanisms of peatland pattern formation may change with climatic conditions, and that this change is reflected in the resource contrast in the vegetation of patterned peatlands.

The main purpose of confronting model predictions with field data, as we performed in this study, is model rejection or refinement. Although the most reliable indicator (resource contrast in the vegetation) corrobo- 

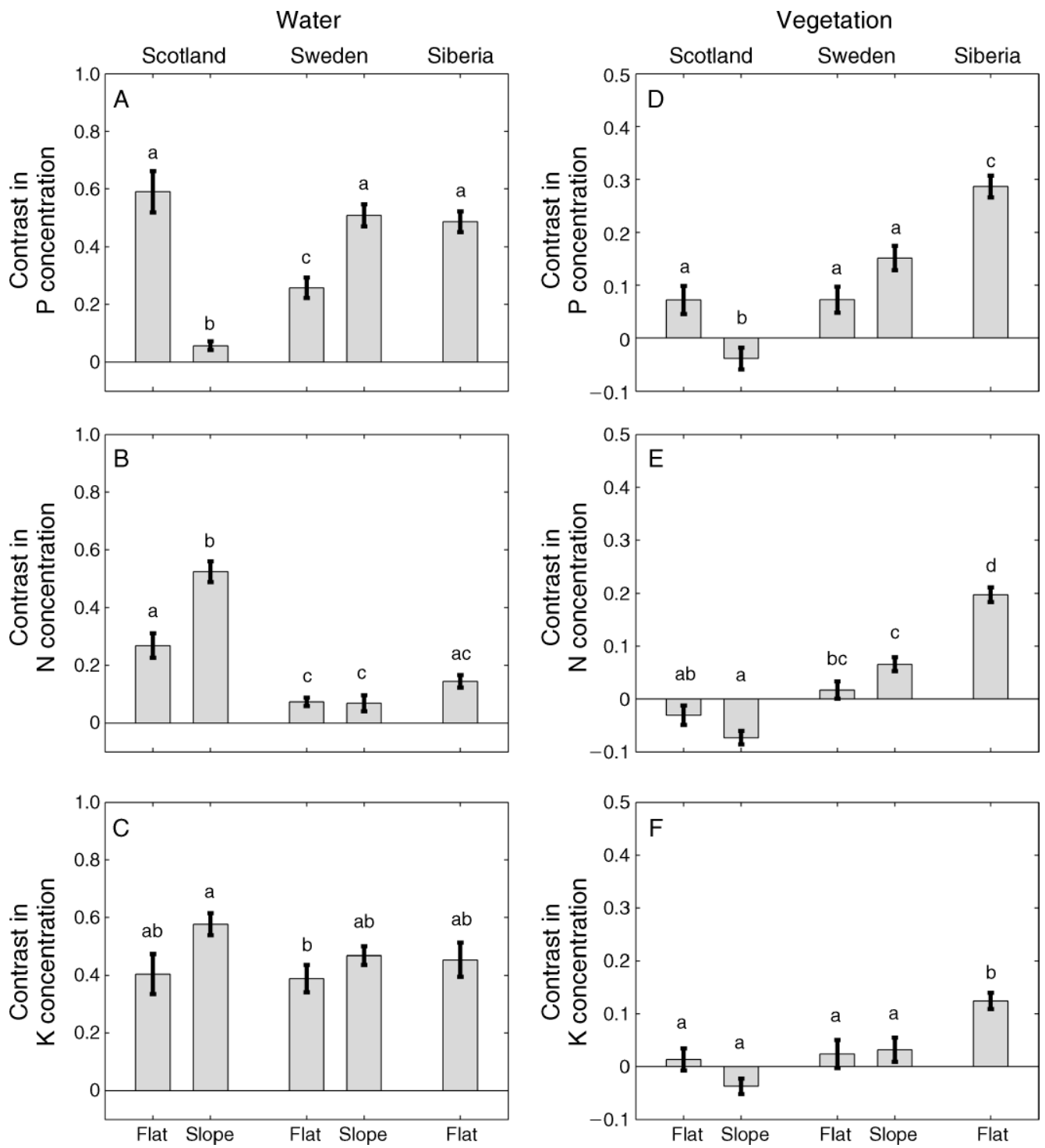

FIG. 4. Hummock-hollow resource contrasts (dimensionless) for nutrient concentrations in (A-C) peatland water and (D-F) vegetation as measured on hummocks and hollows in patterned peatlands in Scotland, Sweden, and Siberia. In all panels the importance of evapotranspiration increases from left (Scotland) to right (Siberia). Different lowercase letters above the data bars indicate significant differences $(P<0.05)$ between pattern-localities; error bars indicate \pm SE.

rated model predictions, the data also provide clear suggestions for model improvement. Contrary to our hypothesis, there were no trends in the contrasts in peatland water nutrient concentrations along the gradient in ET:Prec ratio (Fig. 4A-C). The model that was used to derive our hypotheses assumed continuous plant uptake of nutrients and continuous availability of the dissolved nutrient pool (Eppinga et al. 2009a). Although measurements of peatland water $\mathrm{P}$ concentration in Siberia corroborated these assumptions (Eppinga et al. 2008; Fig. 3A), most measurements of peatland water $\mathrm{P}$ concentration in Scotland and Sweden were below detection limits. Therefore, nutrient transport through advection of water and dissolved P may be lower in the Swedish and Scottish pattern-localities than predicted by reaction-diffusion models on peatland patterning (Rietkerk et al. 2004b, Eppinga et al. 2009a, b). This is in line with the idea that a nutrient-accumulation mechanism is absent in the Scottish and Swedish sites, but also suggests that even in ET-dominated peatlands, nutrient transport may be limited if most $\mathrm{P}$ is quickly adsorbed. The models could be improved by considering nutrient dynamics and nutrient transport in more detail, that is by modeling nutrients in both the dissolved and the 
adsorbed phase and explicitly considering nutrient uptake and nutrient storage by plants as separate processes.

Using nutrient ratios in vegetation as an indicator of nutrient limitation (Olde Venterink et al. 2003, Wassen et al. 2005), our results indicated limitation by $\mathrm{P}$ rather than $\mathrm{N}$ in all three study areas. In general, $\mathrm{N}$ is considered to be more often the limiting nutrient in peatlands (e.g., Malmer et al. 1997), and increased plant growth has been observed in $\mathrm{N}$-addition experiments in one of our study sites (Wiedermann et al. 2007). Therefore, we note that there may be interactive effects between $\mathrm{N}$ addition and $\mathrm{P}$ availability, for example through increased phosphatase activity of plants such as Eriophorum vaginatum (Kroehler and Linkins 1988).

Finally, it is important to note that we sampled a different plant species in each area, which possibly confounds the effect of the gradient in ET:Prec ratio on the resource contrasts. It is difficult to avoid this effect when comparing peatlands in different climates. However, we think that there are two reasons why our approach is robust, despite this potential species effect. First, greenhouse experiments have shown that, when focusing on one plant part of one species (as we did in each study area), the tissue $\mathrm{N}$ and $\mathrm{P}$ concentration is to a large extent determined by the amount of $\mathrm{N}$ and $\mathrm{P}$ supplied to the plants (Güsewell and Koerselman 2002). Also, field fertilization experiments have shown that the effect of fertilizer addition is reflected in $\mathrm{N}$ and $\mathrm{P}$ concentrations within the plants, and that for a given supply of $\mathrm{N}$ and $\mathrm{P}$ there is relatively little interspecific variation (Güsewell and Koerselman 2002). These findings suggest that our sampling design not only captures the hummock-hollow differences in nutrient supply within a pattern-locality, but it also suggests that the observed differences in nutrient supply are not dependent on the plant species that was sampled. Second, if the different rooting patterns of the three plant species had affected the resource contrast, this would have most likely been a weakening effect rather than an explanatory factor. More specifically, in Siberia and Sweden we sampled Carex lasiocarpa and $E$. vaginatum, which are characterized by a long vertical root system (Granberg et al. 2001, Malmer and Wallén 2005), and therefore may be better able to attract nutrients from deeper layers (and thus smooth out possible hummock-hollow differences in nutrient availability) as compared to the more shallow-rooting Rhynchospora alba (Malmer and Wallén 2005) that was sampled in the Scottish site.

Although previous research suggests that the resource contrast in vegetation is a reliable indicator of resource supply, it is important to note that the resource contrast is not entirely independent of the ecosystem context. There may be interactive effects between nutrient supply, hydrological processes and vegetation. Indications of such interactions can be found in the different effect of topography in the Scottish and Swedish pattern-locali- ties (Fig. 4). In Scotland, the resource contrast was higher on flat ground than on slopes. Here, Sphagnum capillifolium and other peat mosses growing on hummocks may be able to hold water and ions within the microform to some extent (Aravena and Warner 1992), which could limit nutrient flow from hummocks to hollows as predicted by previous models (Eppinga et al. 2009a). On slopes (i.e., higher hydraulic gradients), however, advection rates increase, and hence solutes may get "washed out" of hummocks on slopes more quickly than those on flat ground. The lower resource contrasts on slopes might thus be explained by water retention being unable to overcome advective downslope water flow. In Sweden, the resource contrast tended to be higher on slopes. An important difference in that study area was the occurrence of trees on slopes, which may have increased ET rates leading to nutrient accumulation on ridges (see Perspectives..., below). These observations suggest that nutrient supply, water flow, and vegetation may interactively affect the magnitude of the resource contrast in patterned peatlands.

\section{Perspectives: the nutrient-accumulation mechanism and peatland patterning}

Our vegetation data revealed that the resource contrast changed along a gradient in the ET:Prec ratio (Table 1; Fig. 4D-F). Previous theoretical studies suggest that a strongly positive resource contrast, as observed in the Siberian pattern-locality, may reflect the occurrence of the nutrient-accumulation mechanism. Further model development and further expansion of the empirical data set could be used to examine whether the importance of nutrient accumulation for peatland patterning can be estimated from data that are already available at a global scale, such as the annual ET:Prec ratio based on global climate data (e.g., Meehl et al. 2007). Although more work is clearly needed, our current study suggests that the Swedish pattern-localities may be close to the ET:Prec ratio where nutrient accumulation becomes important, as we will now further speculate upon. Trees in particular may stimulate ET rates (Rietkerk et al. 2004b). Resource contrasts for P and $\mathrm{N}$ in vegetation tended to be slightly higher in the Swedish pattern with trees (slope pattern), but this difference was not significant (Fig. 4D, E). Our measurement period took place relatively late in the growing season, when ET rates may be close to the yearly maximum (Sagerfors et al. 2008). During that period, ET losses may exceed inputs via precipitation (Sagerfors 2007). We speculate that during this short period, there might be some nutrient accumulation on hummocks. However, the resource contrasts in the Swedish patternlocalities were significantly lower than in the Siberian pattern-locality (Fig. 4D, E), suggesting that in the Swedish pattern-localities the nutrient-accumulation mechanism occurs not long or strongly enough to drive pattern formation and amplification of resource contrasts. This could imply that the Swedish pattern- 


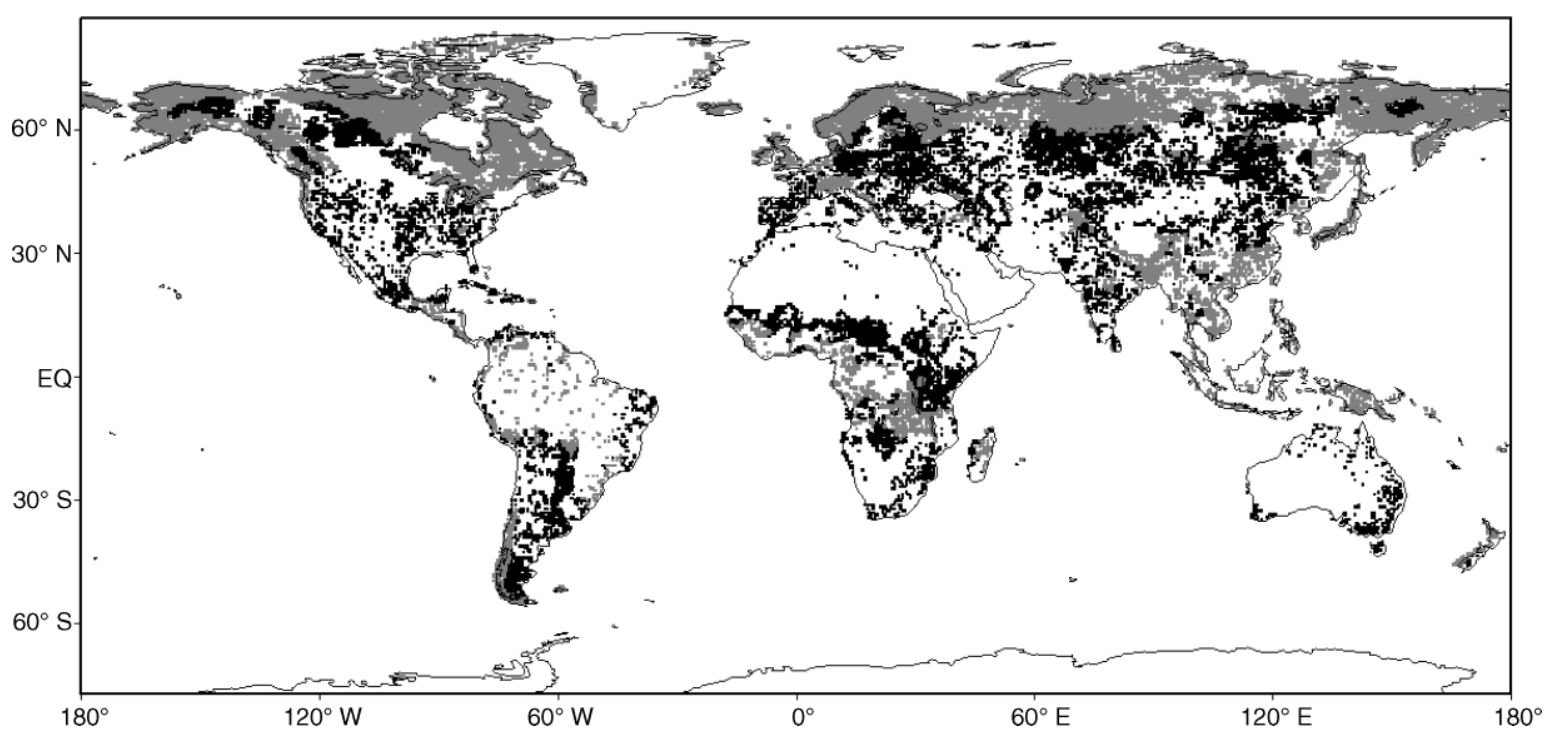

FIG. 5. Map showing the global distribution of peatland ecosystems (gray and black areas) and the peatland areas where the long-term annual average evapotranspiration: precipitation ratio is larger than 0.6 (black areas). We speculate that in these black areas, the nutrient-accumulation mechanism might affect peatland patterning. The following data sources were used: Lehner and Döll (2004) for wetland cover, Mitchell et al. (2004) for long-term annual average precipitation, and Fekete et al. (2002) for longterm annual evapotranspiration.

localities are close to the threshold where the nutrientaccumulation mechanism may become relevant for peatland pattern formation. Based on this assumption, we hypothesize that the nutrient-accumulation mechanism may become relevant in peatlands with a considerable tree and shrub cover and with an ET:Prec ratio of at least $\sim 0.6$ (on an annual basis). It should be noted that an ET:Prec ratio of $\sim 0.6$ or higher would be a rather strong climatic constraint that is not met in most maritime climates (Fig. 5). However, this threshold would suggest that the nutrient-accumulation mechanism may be relevant in three of the four largest peatland regions in the world: the West Siberian basin, the Pripyat basin, and Glacial Lake Agassiz (Glaser et al. 2004). It is important to note that data based on annual means cannot be an exact predictor because they do not capture the temporal and spatial variability in the strength of the nutrient-accumulation mechanism. Nevertheless, they may assist in identifying regions where the mechanism may be important (Fig. 5).

Peatlands worldwide are affected by changing patterns in precipitation and ET (Meehl et al. 2007) and changes in temperature that may affect the length of the vascular plant growing season (Eppinga et al. 2009b). Future theoretical and empirical studies that build upon the work presented in our present study may provide better understanding of how these climatic changes may affect the functioning of patterned peatlands. The work presented in this study suggests that climate change alters ecosystem functioning by changing the contribu- tion of pattern-driving mechanisms to the redistribution of water and nutrients in peatlands.

\section{ACKNOWLEDGMENTS}

We thank R. S. Clymo, L. G. Larsen, and A. S. Reeve for comments that improved the manuscript; Hugo de Boer for assistance with Fig. 5; Rob Dewar and the National Trust for Scotland for granting access to the Inverewe field site; Helen de Waard, Arnold van Dijk, and Dineke van de Meent for help with the laboratory analyses; Wladimir Bleuten, Wiebe Borren, Olga Pisarenko, Andrej Korolyuk, Jan Hrupacék, and Frans Wassen for assistance in the field; the Research Council Earth and Life Sciences of the Netherlands Organization of Scientific Research (NWO-ALW) for a VIDI grant to M. Rietkerk; and the UK Natural Environment Research Council for an Advanced Fellowship (NER/J/S/2001/00799) to L. R. Belyea.

\section{Literature Cited}

Aravena, R., and B. G. Warner. 1992. Oxygen-18 composition of Sphagnum, and microenvironmental water relations. The Bryologist 95:445-448.

Belyea, L. R. 2007. Climatic and topographic limits to the abundance of bog pools. Hydrological Processes 21:675-687.

Belyea, L. R., and A. J. Baird. 2006. Beyond "the limits to peat bog growth": Cross-scale feedback in peatland development. Ecological Monographs 76:299-322.

Belyea, L. R., and R. S. Clymo. 2001. Feedback control of the rate of peat formation. Proceedings of the Royal Society of London B 268:1315-1321.

Belyea, L. R., and N. Malmer. 2004. Carbon sequestration in peatland: patterns and mechanisms of response to climate change. Global Change Biology 10:1043-1052.

Binkley, D., and S. C. Hart. 1989. The components of nitrogen availability in forest soils. Advances in Soil Science 10:57112.

Bridgham, S. D., K. Updegraff, and J. Pastor. 2001. A comparison of nutrient availability indices along an ombrp- 
trophic-minerotrophic gradient in Minnesota wetlands. Soil Science Society of America Journal 65:259-269.

Efron, B., and R. J. Tibshirani. 1993. An introduction to the bootstrap. Chapman and Hall, New York, New York, USA.

Eppinga, M. B., P. C. de Ruiter, M. J. Wassen, and M. Rietkerk. 2009a. Nutrients and hydrology indicate the driving mechanisms of peatland surface patterning. American Naturalist 173:803-818.

Eppinga, M. B., M. Rietkerk, W. Borren, E. D. Lapshina, W. Bleuten, and M. J. Wassen. 2008. Regular surface patterning of peatlands: confronting theory with field data. Ecosystems 11:520-536.

Eppinga, M. B., M. Rietkerk, M. J. Wassen, and P. C. de Ruiter. 2009b. Linking habitat modification to catastrophic shifts and vegetation patterns in bogs. Plant Ecology 200:5368.

Fekete, B. M., C. J. Vorosmarty, and W. Grabs. 2002. Highresolution fields of global runoff combining observed river discharge and simulated water balances. Global Biogeochemical Cycles 16:1042.

Foster, D. R., G. A. King, P. H. Glaser, and H. E. Wright, Jr. 1983. Origin of string patterns in boreal peatlands. Nature 306:256-258.

Glaser, P. H., D. I. Siegel, A. S. Reeve, J. A. Janssens, and D. R. Janecky. 2004. Tectonic drivers for vegetation patterning and landscape evolution in the Albany River region of the Hudson Bay Lowlands. Journal of Ecology 92: $1054-1070$.

Granberg, G., I. Sundh, B. H. Svensson, and M. Nilsson. 2001. Effects of temperature, and nitrogen and sulfur deposition, on methane emission from a boreal mire. Ecology 82:19821998.

Güsewell, S., and W. Koerselman. 2002. Variation in nitrogen and phosphorus concentrations of wetland plants. Perspectives in Plant Ecology, Evolution and Systematics 5:37-61

Ingram, H. A. P. 1983. Hydrology. Pages 67-158 in A. J. P. Gore, editor. Ecosystems of the world 4A. Mires: swamp, bog, fen and moor. Elsevier, Amsterdam, The Netherlands.

Jonasson, S., and G. R. Shaver. 1999. Within-stand nutrient cycling in arctic and boreal wetlands. Ecology 80:2139-2150.

Kroehler, C. J., and A. E. Linkins. 1988. The root surface phosphatases of Eriophorum vaginatum: effects of temperature, $\mathrm{pH}$, substrate concentration and inorganic phosphorus. Plant and Soil 105:3-10.

Larsen, L. G., J. W. Harvey, and J. P. Crimaldi. 2007. A delicate balance: ecohydrological feedbacks governing landscape morphology in a lotic peatland. Ecological Monographs 77:591-614.

Lehner, B., and P. Döll. 2004. Development and validation of a global database of lakes, reservoirs and wetlands. Journal of Hydrology 296:1-22.

Levin, S. A. 1992. The problem of pattern and scale in ecology. Ecology 73:1943-1967.

Malmer, N., G. Svensson, and B. Wallén. 1997. Mass balance and nitrogen accumulation in hummocks on a South Swedish bog during the late Holocene. Ecography 20:535-549.

Malmer, N., and B. Wallén. 2005. Nitrogen and phosphorus in mire plants: variation during 50 years in relation to supply rate and vegetation type. Oikos 109:539-554.

MathWorks. 2008. MATLAB, version 7.7.0. The MathWorks, Natick, Massachusetts, USA.

Meehl, G. A., et al. 2007. Global climate projections. Pages 747-845 in S. D. Solomon, D. Qin, M. Manning, Z. Chen, M. Marquis, K. B. Averyt, M. Tignor, and H. L. Miller, editors. Climate change 2007: The physical science basis. Contribution of Working Group I to the Fourth Assessment Report of the IPCC. Cambridge University Press, New York, New York, USA.

Mitchell, T. D., T. R. Carter, P. D. Jones, M. Hulme, and M. New. 2004. A comprehensive set of high resolution grids of monthly climate for Europe and the globe: the observed record (1901-2000) and 16 scenarios (2001-2100). Tyndall Centre Working Paper 55.

Olde Venterink, H. G. M., M. J. Wassen, A. W. M. Verkroost, and P. C. de Ruiter. 2003. Species richness-productivity patterns differ between N-, P-, and K-limited wetlands. Ecology 84:2191-2199.

Quinton, W. L., and N. T. Roulet. 1998. Spring and summer runoff hydrology of a subarctic patterned wetland. Arctic and Alpine Research 30:285-294.

Reeve, A. S., D. I. Siegel, and P. H. Glaser. 2000. Simulating vertical flow in large peatlands. Journal of Hydrology 227: 207-217.

Rietkerk, M., S. C. Dekker, P. C. de Ruiter, and J. Van de Koppel. 2004b. Self-organized patchiness and catastrophic shifts in ecosystems. Science 305:1926-1929.

Rietkerk, M., S. C. Dekker, M. J. Wassen, A. W. M Verkroost, and M. F. P. Bierkens. 2004a. A putative mechanism for bog patterning. American Naturalist 163:699-708.

Rietkerk, M., and J. Van de Koppel. 2008. Regular pattern formation in real ecosystems. Trends in Ecology and Evolution 23:169-175.

Sagerfors, J. 2007. Land-atmosphere exchange of $\mathrm{CO}_{2}$, water and energy at a boreal minerotrophic mire. Dissertation. Acta Universitatis agriculturae Sueciae, 2007:4. Umeå, Sweden.

Sagerfors, J., A. Lindroth, A. Grelle, L. Klemedtsson, P. Weslien, and M. Nilsson. 2008. Annual $\mathrm{CO}_{2}$ exchange between a nutrient-poor, minerotrophic, boreal mire and the atmosphere. Journal of Geophysical Research, Biogeosciences 113:G01001.

Semenova, N. M., and E. D. Lapshina. 2001. Description of the West Siberian plain. Pages 10-22 in W. Bleuten and E. D. Lapshina, editors. Carbon storage and atmospheric exchange by West Siberian peatlands. Department of Physical Geography, Utrecht University, Utrecht, The Netherlands.

Shachak, M., B. Boeken, E. Groner, R. Kadmon, Y. Lubin, E. Meron, G. Ne'eman, A. Perevolotsky, Y. Shkedy, and E. D. Ungar. 2008. Woody species as landscape modulators and their effect on biodiversity patterns. BioScience 58:209221.

Sjörs, H. 1961. Surface patterns in boreal peatland. Endeavour 20:217-223.

Solé, R. V., and J. Bascompte. 2006. Self-organization in complex ecosystems. Princeton University Press, Princeton, New Jersey, USA.

SPSS. 2001. SPSS statistics, version 14.0. SPSS, Chicago, Illinois, USA.

Van de Koppel, J., J. C. Gascoigne, G. Theraulaz, M. Rietkerk, W. M. Mooij, and P. M. J. Herman. 2008. Experimental evidence for spatial self-organization and its emergent effects in mussel bed ecosystems. Science 322:739-742.

Van der Valk, A. G., and B. G. Warner. 2009. The development of patterned mosaic landscapes: an overview. Plant Ecology 200:1-7.

Wassen, M. J., H. G. M. Olde Venterink, and E. O. A. M. de Swart. 1995. Nutrient concentrations in mire vegetation as a measure of nutrient limitation in mire ecosystems. Journal of Vegetation Science 6:5-16.

Wassen, M. J., H. G. M. Olde Venterink, E. D. Lapshina, and F. Tanneberger. 2005. Endangered plants persist under phosphorus limitation. Nature 437:547-550.

Wetzel, P. R., A. G. Van der Valk, S. Newman, D. E. Gawlik, T. Troxler Gann, C. A. Coronado-Molina, D. L. Childers, and F. H. Sklar. 2005. Maintaining tree islands in the Everglades: nutrient redistribution is the key. Frontiers in Ecology and Environment 3:370-376.

Wiedermann, M. M., A. Nordin, U. Gunnarsson, M. B. Nilsson, and L. Ericson. 2007. Global change shifts vegetation and plant-parasite interactions in a boreal mire. Ecology 88:454-464. 
APPENDIX A

Description of the study areas (Ecological Archives E091-167-A1).

\section{APPENDIX B}

Details on the processing of water samples (Ecological Archives E091-167-A2). 